\title{
Evaluation of Serum Albumin Utilization in Inpatient at a Private Hospital in Bangkok
}

\author{
Pornanong ARAmWiT* and Narat KASETTRATAT \\ Clinical Pharmacy Department, Faculty of Pharmaceutical Sciences, Chulalongkorn University, \\ Payathai Road, Bangkok 10330, Thailand
}

(Received January 16, 2004; Accepted May 27, 2004)

\begin{abstract}
Serum albumin is widely used for the treatment of hypovolemia, shock, hyperbilirubinemia or acute liver failure. However, serum albumin itself may have a significant effect on the action, elimination or distribution of other medications in blood which may affect the outcome of the treatment. Besides, it is also expensive and, most important, can be a carrier for many life-threatening diseases such as AIDS. The objective of this study is to evaluate the serum albumin utilization in inpatient at a private hospital in Bangkok, Thailand. Descriptive, retrospective study was designed to monitor the $25 \% \mathrm{w} / \mathrm{v}$ serum albumin orders over a four-month period. The background information, doses and rational of serum albumin orders, other medication orders, side effects, the interaction between serum albumin and other medications, the laboratory results and also clinical outcome of the patients were recorded. From the medication orders of 74 inpatients, there were 104 orders of serum albumin for 9 indications. The most common indications were hypoalbuminemia $(48 \%)$ and cirrhosis $(9 \%)$. From the total number of serum albumin orders, there were only 67 orders $(64.4 \%)$ prescribed with rational dose and duration under appropriate indications. Totally about $35.6 \%$ of serum albumin orders were prescribed with improper indications such as edema, anemia or coronary artery bypass grafting. Out of $35.6 \%, 14$ $\%$ of the orders were prescribed to contraindicated patients. No side effect of serum albumin infusion was found during this study. The result indicates the over-utilization of serum albumin and specific guideline for using this agent should be set in every hospital.
\end{abstract}

Key words_ _ serum albumin, utilization, inpatients

\section{INTRODUCTION}

Serum albumin is a major water-soluble protein in human body. It has important roles in controlling colloidal osmotic pressure and has ability to bind insoluble substances such as bilirubin, fatty acids and some slightly soluble medications in the blood stream. Infusion of serum albumin intravenously may affect the pharmacokinetics and free level of other drugs, and also blood pressure of the patients.

Serum albumin continues to be the most frequently used plasma expander especially in premature babies and neonates. ${ }^{1)}$ Besides using as plasma expander, there are several indications of serum albumin for intravenous administration. The common indications are shock, hypovolemia, hyperbilirubinemia, ascite, transient hypoalbuminemia, cerebral edema, acute nephrosis and malnutrition. However, patients with hypersensitivity to serum albumin together with severe cardiac diseases and chronic anemia are contraindicated for this intravenous solution. Although serum albumin has many advantages, it is expensive

e-mail: annablee@ hotmail.com and, the most important, can be a carrier of many blood-born diseases such as mad cow diseases or acquired immunodeficiency diseases (AIDS) .

There are several reports on the abuse or overuse of serum albumin especially in the old time period. ${ }^{2-4)}$ The inappropriate use of this agent accounted for an enormous amount of annual expenditure in several hospitals all around the world. ${ }^{5,6)}$ Recently, Tanzi et al evaluated the use of serum albumin in adult and pediatric patients in 53 institutions in United Stated and found that albumin was inappropriately prescribed for $57.8 \%$ of adult patients and $52.2 \%$ of pediatric patients. ${ }^{7)}$ Similar result was found in other countries such as Spain which showed only $8.1 \%$ appropriated use of serum albumin in a study with 197 subjects. ${ }^{8)}$ The result from study in Japan indicated that reconsidering the criteria for serum albumin administration may result in reducing the albumin use. ${ }^{3)}$ There is no study to evaluate the use of serum albumin in Thailand. However, the similar results as other countries can be predicted.

Even general clinical practice guidelines were created in many hospitals around the world, the uses of this intravenous preparation are still questiona- 
ble. ${ }^{2,8,9)}$ Having a strict and more specific guideline for the use of this product in hospital formulary show a significant improve on its usage. ${ }^{1,6)}$

In Thailand, there is no specific guideline for the use of serum albumin resulting in an improper use. The objective of this study is to evaluate the serum albumin utilization in inpatient at one private hospital in Bangkok. The results from this pilot study can be used for developing an appropriate guideline for this intravenous agent and also other medications.

\section{MATERIALS AND METHODS}

A descriptive, retrospective study was designed using the questionnaires to monitor the prescription of $25 \% \mathrm{w} / \mathrm{v}$ serum albumin for inpatients during the four months period. The first questionnaire was used to get the background information, the orders of serum albumin including the doses and rational of uses, other medication orders and the laboratory results from medical records, patient profiles and medical notes. The second set of questionnaire was designed to get the information regarding the side effects from this major blood protein, the interaction between serum albumin and other medications, and also clinical outcome by interviewing the subjects. During this time period, there were 104 serum albumin orders from 36 male and 38 female patients.

\section{RESULTS AND DISCUSSION}

From the total of 104 serum albumin orders, about $49 \%$ of the orders are prescribed to patients with age more than 70 years old. The rest of the orders are prescribed mainly to the patients at 50 to 69 years old. Admission reasons are widely distributed. The most common admission reasons are cardiovascular and gastrointestinal diseases (28.38\% equally). About 17 $\%$ of the subjects admit from respiratory problems while $13.16 \%$ have renal diseases. The remain of the subjects are admitted from infection, oncology, endocrine diseases and accident at $8.11 \%, 2.7 \%, 1.35 \%$ and $1.35 \%$, respectively. Serum albumin is prescribed to a patient for one to four indications. However, most of the orders, $51 \%$, are prescribed for only one indication. Sixty-seven serum albumin orders, or 64.4 $\%$, are dispensed within the scope of indications mentioned in AHFS Drug Information Book, 2002 which are hypoalbuminemia, hypovolemia, cirrhosis, hyperbilirubinemia, shock, ascites, malnutrition, adult respiratory distress syndrome and cerebral edema. Figure 1 shows the percentage of orders for each

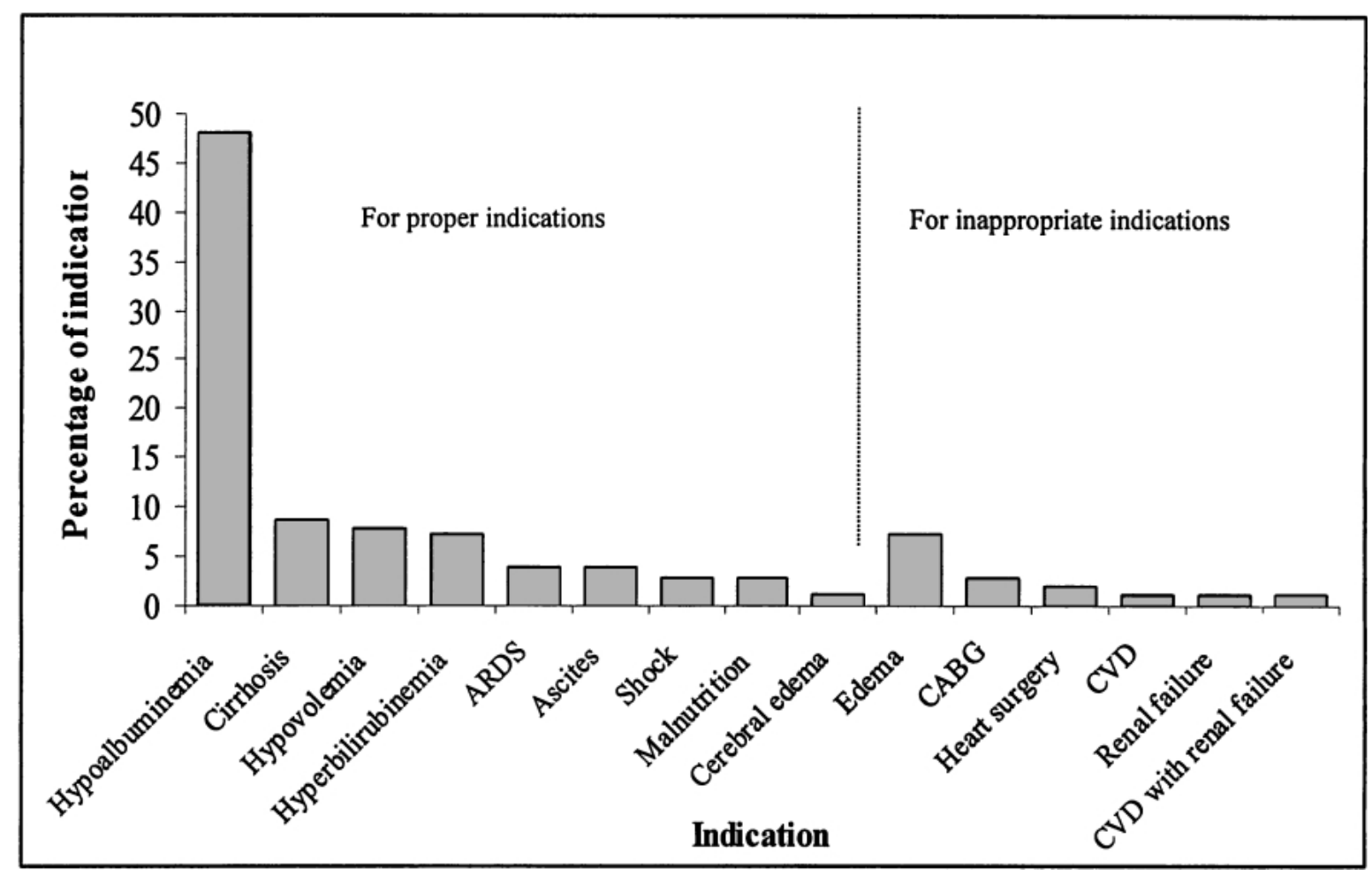

Fig. 1. The Percentage of Each Indication for Serum Albumin Orders 
indication. However, 15 orders (14\%) are prescribed inappropriately to contraindicated patients since serum albumin has no indication to use in patients with edema, coronary artery bypass grafting (CABG), cardiovascular diseases or renal failure unless necessary which are not shown in these patients. The most common indication is hypoalbuminemia. From 74 patients, there are 32 patients have serum albumin orders because of the low level of serum albumin in the blood. The normal level of serum albumin in ordinary people is about 3.5 to $5 \mathrm{~g} / \mathrm{dl} .{ }^{10)}$. Out of 32 patients, 21 patients had serum albumin in the blood less than $3 \mathrm{~g} / \mathrm{dl}$ while 11 patients received intravenous serum albumin even their serum albumin level was in the range of 3 to $3.5 \mathrm{~g} / \mathrm{dl}$ which may be considered as unnecessary use. Even though some literatures suggest that administration of serum albumin in hypoalbuminemia patients should be prescribed only when serum albumin level is less than $2.5 \mathrm{~g} / \mathrm{dl},{ }^{2)}$ many prescribers believe that serum albumin preparation should be used to replace the blood volume in hypovolemia or shock condition. Also, binding property of albumin preparation with bilirubin may be helpful for the treatment of hyperbilirubinemia. Because of the water-retention property, it is believed that serum albumin can be used for the treatment of edema. The average pre-administration of patients' serum albumin level is $2.79 \pm 0.27 \mathrm{~g} / \mathrm{dl}$. The length of serum albumin administration range from 1-5 days and the total of serum albumin prescribed are from 25 grams for up to 450 grams during this hospital visit. The average of albumin preparation administered to this group of patients is 141.41 grams. After administration, the average serum albumin level is $3.87 \pm 0.64$ $\mathrm{g} / \mathrm{dl}$. Most patients, $72.16 \%$, administered albumin preparations are at chronic stage while $27.84 \%$ of patients are in acute stage.

In this study, the prescribers do not calculate the expected elevation in albumin concentration before use. However, calculation of the albumin dose in each patient from retrospective information showed that only 22 patients $(29.73 \%)$ received proper dose of serum albumin during hospital visit. About $58 \%$ of the subjects got unnecessary high dose while $12.16 \%$ received under dose of albumin.

A study published in British Medical Journal reports that the use of plasma albumin in severely ill patients increased about $6 \%$ in mortality rate. ${ }^{11}$ However, only 2 patients in this study with cerebral edema and severe cardiac diseases were considered as critical ill by physicians' opinion. From previous report, these cases should not be treated with serum albumin and degree of severity in patients should also be considered as a factor for adequate use of albu$\min$.

The result also shows that the doctors prescribed serum albumin to 22 cardiac diseases or chronic anemia patients $(21.6 \%)$. Patients with those conditions should be avoided using this agent even for a short period of time unless concomitant necessary such as with hyperbilirubinemia. Overall results show that serum albumin was over-utilized. However, no side effect or significant drug interaction between serum albumin and other prescribed medications is found during this study.

Several literatures indicated that there is no clear benefit of using serum albumin instead of artificial colloids and, even in some cases, crystalloid or synthetic colloid solutions such as hetastarch, mannitol may be better alternative because of their safety and economical reason. ${ }^{12)}$ Because of these properties, the use of serum albumin should therefore be restricted. It may be possible to cut back on albumin by reconsidering the criteria of its administration and setting the specific guidelines for the clinical use of blood preparations. The guideline should clearly specify only conditions that albumin preparation can be prescribed such as hypoalbuminemia patients in acute stage with serum albumin less than $2.5 \mathrm{~g} / \mathrm{dl}$ or hyperbilirubinemia condition with total bilirubin is significantly higher than $1.0 \mathrm{mg} / \mathrm{dl}$. Expected elevation in albumin concentration should be calculated before use of serum albumin. Besides, approval form must be signed by prescribers before administration. This form will be a final reminder of necessary use for this blood product in each case. These processes not only promote a more rational use, but also make a significant contribution to the rising cost of health care.

\section{CONCLUSION}

Serum albumin was over-prescribed in this private hospital in Bangkok which is similar to the inappropriate use of this blood-generated agent in most hospitals around the world. Even for the indication such as hypoalbuminemia which is the most common indication, it should be prescribed with special precaution and follow specific guideline. Many artificial colloidal solutions may be an alternative with 
many advantages including the cost and lower the risk of blood-born infection.

\section{REFERENCES}

1) Soderlind M., Salvignol G., Izard P., Lonnqvist P. A., Pediatr. Anaesth., 11, 685-689 (2001).

2) Finelli C., Alfano V., Pasanisi F., Marra M., Violante G., Alfonsi L., Scalfi L., Contaldo F., Clin. Nutr., 20, 183-185 (2001).

3) Yoshida H., Uchida K., Murata O., Kamiya A., Yakugaku Zasshi, 120, 1227-1231 (2000) .

4) Gianarkis D. G., Kucich J. M., Liotta C. A., Hosp. Pharm., 26, 434-436, 455 (1991).

5) Alexander M. R., Stumpf J. L., Nostrant T. T., Khanderia U., Eckhauser F. E., Colvin C. L., DICP., 23, 214-217 (1989) .

6) Debrix I., Combeau D., Stephan F., Benomar A., Becker A., Pharm. World Sci., 21, 11-16
(1999) .

7) Tanzi M., Gardner M., Megellas M., Lucio S., Restino M., Am. J. Health Syst. Pharm., 60, 1330-1335 (2003).

8) Vargas E., De Miguel V., Portoles A., Avendano C., Ambit M. I., Torralba A., Moreno A., Eur. J. Clin. Pharmacol., 52, 465-470 (1997).

9) Anonymous, Med. J. Aust., 154, 657-660 (1991) .

10) Todd M., "Criteria for Drug Use Evaluation," ed. by The American Society of HealthSystem Pharmacists, Bethesda, MD, 1993, pp. 524-546.

11) Cochrane Injuries Group Albumin Reviewers, BMJ., 317, 235-240 (1998).

12) Natsch S., Van Leeuwan S. J., De Jong R., Hekster Y. A., J. Clin. Pharm. Ther., 23, 17983 (1998). 